\title{
Understanding Awareness and Consumption of Folic Acid among reproductive age women in Bahirdar Town, North west Ethiopia: a qualitative study.
}

betelihem Manaye

Amhara regional health bureau

Taye Zeru ( $\boldsymbol{D}$ zerutaye@gmail.com )

Amhara Public Health Institute https://orcid.org/0000-0003-0736-2955

\section{Research Article}

Keywords: Folic Acid, Neural tube defects, Bahir-Dar,North west Ethiopia

Posted Date: March 20th, 2020

DOI: https://doi.org/10.21203/rs.3.rs-18100/v1

License: (c) (1) This work is licensed under a Creative Commons Attribution 4.0 International License.

Read Full License 


\section{Abstract}

Background: Adequate maternal consumption of folic acid before pregnancy and during the early weeks of gestation can reduce the risk of having a child with a neural tube defect. Current guidance recommends that all women who could become pregnant should take a folic acid supplement before conception and until the twelfth week of pregnancy. The aim of the study was to understand women's awareness and folic acid consumption among reproductive age women in Bahir Dar town.

Methods: A descriptive qualitative research approach, implementing face-to-face focus group (FGD) discussions was done during the month of 2019. The FGD audio was recorded and translated to English, and then content and thematic analysis was done.

Result: Forty two (42) participants participated through four (4) focus group discussions. Almost all respondents did not know what foods contain folic acid. Even though Two (2) participants of the FGDS had heard/seen information about children who had Hydrocephalus / Spinal bifida they did not know the causes of neural tube defects.

Conclusions : All reproductive age women that participated in the study had no under- standing of the importance of eating foods rich in folic acid in the months prior to pregnancy, and did not know food items containing high levels of folic acid.

\section{Background}

Neural tube defects (NTDs), a common group of central nervous system anomalies, comprise a major public health problem. It is estimated that approximately 300,000 babies are born each year with NTDs worldwide [1].According to the World Health Organization (WHO) in 2010, an estimated 270,000 neonatal deaths globally were attributable to congenital anomalies, with NTDs being one of the most serious and most common of these anomalies [2-3].

Both the birth and total prevalence of NTD have declined during the past three decades among high income countries [4-6]. Evidence suggests that the reduction in the birth prevalence of NTDs is largely due to termination of pregnancy after the introduction of routine serum alpha $\mathrm{N}$ fetoprotein measurements and advances in ultrasonography resolution for in utero early detection and termination of affected pregnancies [5-6].Additionally, improvements in folic acid supplementation have contributed to the reduction in total prevalence of NTDs [6].

For example, the incidence of myelomeningocell in Seattle, Washington, USA, was 5 per 10,000 births in 1981-1982, which then declined to 0.5 in 2001 [7]. The prevalence of NTDs in England and Wales was 38.0 per 10,000 live births in 1965 , which steadily declined to 1.4 in 1997 , a reduction of $96 \%$ [8]. Contrary to the developed world, prevalence of birth NTDs in developing countries is still high, with reported incidence as high as 130 per 10,000 births [9]. 
NTD prevalence in Ethiopia is not clearly known, and the country currently has no national preventive strategies. A retrospective chart review from Addis Ababa teaching hospitals revealed the overall prevalence of NTDs to be $6.1 / 1000$ births [10]. The review concludes by recommending prospective studies to understand the real burden of NTDs.

A community-based cross-sectional study conducted in Northwest Ethiopia, Adet showed that from a total of 422 participants, only $79(18.7 \%)$ of women have heard before about preconception folic acid supplementation. From those who have heard about pre- conception folic acid supplementation, only 67 (15.9\%) participants have correctly mentioned the right time of initiation for preconception folic acid supplementation [11].

\section{Methods}

Study design: A community based exploratory qualitative study was done

Setting: Bahir Dar city is the capital city of Amhara Regional State, which is located in the North West of Ethiopia; $565 \mathrm{~km}$ from Ad- dis Ababa. The city administration is classified for administrative purposes into nine urrbn and nine rural Kebeles and four satellite towns. The two study sites were Keble 16 and Sebat Amit which are found in Bahir Dar town.

Data collections process: Focus group discussions (FGDS) were carried out by trained qualitative data collectors composed of health professionals to guide the FGDS, audio visual professionals for recording of the audio. A supervisor from the Amhara Public Health Institute was assigned to observe the activity.

Data processing and analysis: Data was collected using a pretested questionnaire and the collected data was transcribed and trans- lated. Analysis was conducted for content and theme.

Ethical Considerations: A letter of per- mission and support from Amhara Public Health Institute was obtained, and respective authorities in the Bahir Dar City Administration were informed.; Individual informed consent was obtained from each FGD participant after explaining the purpose of the study clearly. In order to keep confidentiality of study participants, an identity number was used for each interviewee. Respondents were informed that they had the right to refuse answering questions or withdraw in the middle of questions if they were not comfortable. Their privacy was secured by arranging a convenient time to complete the interview and to record their voice. Participating in the re-search project was not designed to provide incentives for the interviewees, but the knowledge generated from the research may be important in improving awareness level of pre- conception intake of folic acid for women at reproductive age.

\section{Result}

\section{Socio demographic characteristics}


In total, forty two participants (22 from kebele 16 and 20 from Sebatamit) participated through four focus group discussions. Of the forty-two participants, 16 (38\%) were students (aged 10-19 years) and 8 $(19 \%)$ were married women (aged 20 to 24 years) who had no previous births. Seventeen percent $(17 \%)$ of participants were currently pregnant, and twenty-six (26\%) percent of participants were married women who had children.

\section{Nutritional meal awareness}

Almost all respondents responded that nutritional meal meant foods from different food groups that lead to healthy growth and development of the body. Participants also defined a nutritional meal for all children beyond the age of six months as foods such as fruit, cabbage, butter, milk, potatoes, and meat. Respondents indicated that were important during pregnancy to strengthen and protect the body from diseases, to promote positive mental health, to prevent anemia, and to avoid unwanted weight.

The foods that were taken most often during pregnancy were listed by the respondents as" fruit, carrot, cabbage, banana, milk, fish, meat, fruits, wheat, red teff in the forms of porridge, peas, and beans. The respondents indicated that the foods to be avoided during pregnancy were sugar, raw meat, alcohol, chat, cigarettes, and hot drinks xucj as coffee and tea. Participants incor rectly believed that these foods would in- crease the amniotic fluid during pregnancy.

"I have eaten, fruit, cabbage, difin misir and Abukado (in Amhric) during my pregnancy".(Mother from FGD2 Bahir-Dar sebat amit).

Finally all focus group discussions participants agreed that women should eat nutritious foods as often as possible, because it has a significant impact on the health of the fetus.

\section{Media use habit}

Thirty two (32) participants of the focus group discussions owned televisions, while twenty participants owned a radio; five participants owned both a television and radio. Regarding media use habit, thirty-six per- cent $(36 \%)$ of participants most often watch

EBS TV, twenty four percent (24\% ) watch Amhara TV, fourteen percent (14\%) watch Kana TV, and Fana and Addis TV each were watched ten percent (10\%) of participants.

Few participants of the FGDs remembered hearing or seeing about nutrition related ad- vertisement on radio or TV.

"We have heard programs transmitted through FM 96.9 Bahirdar which is called Minenamakirlwoowo program. " (in Amahric)."(Mother from FGD1 Bahir-Dar kebele 16 and Bahirdar sebatamit)

Hydrocephalus and spinal bifida awareness 
Two participants had heard about children who had Hydrocephalus and spinal bifida, and they thought that it was caused by mothers who didn't eat enough food and who had diabetes mellitus. The two participants also had heard that Hydrocephalus and spinal bifida were the result of actions during the delivery process.

"What we think about the problem is that, child head pulled by instrument and not prop-erly managed during delivery was the causes of spinal bifida" (Mothers from FGD 1 Bahir- dar kebele

16).

\section{Folic acid awareness and utilization}

None of the participants of the FGDS knew about folic acid (vitamin b9) and its utilization. They also lacked awareness about the types of food that are high in folic acid con-tent. Further, the respondents were unaware of when folic acid should be taken.

"The types of food containing folic acids are Atimit, Genfo, mirinda(In Amharic)" (Mother from FGD1 Bahir-Dar).

Even though they didn't know about folic acid, Respondents felt that information about folic acid could most effectively be transmitted through microphones, Keble meetings, the Women's Health Development Army, during anenatal care visits at health facilities, and through school mini media. "The type of media channel used for nutri- tion related advertisements should transmit through Health extension workers for the com-munity and school mini media for students and during ANC follow up in the health cen-ter, "(Mother from FGD1 Bahir-Dar kebele 16.)

\section{Folic acid rich foods access}

Participant shared that they had access to eggs, milk, poultry, meat, green leafy vegetables and avocado in the markets around them, but they were not aware that those foods were folic acid rich foods.

\section{Discussion}

The majority of the findings in the study identified similarities in the mothers' under- standing of the benefits of folic acid consumption, irrespective of the mothers' age or birth outcome. This study identified that all mothers were unaware of the benefits of consuming folic acid, which could prevent, NTD in the early weeks of pregnancy [12]. Moreover, none of the mothers knew alternate sources of folic acid through alternate foods, such as leafy vegetables, which is commensurate with the findings of Yeasmin and Regmi[13].

Awareness level in the Bahir Dar study area is much lower than a community-based cross-sectional study conducted in Northwest Army, during anti natal care visits at health facilities, and through school mini media. "The type of media channel used for nutrition related advertisements should transmit through 
Health extension workers for the com- munity and school mini media for students and during ANC follow up in the health center, "(Mother from FGD1 Bahir-Dar kebele 16.)

\section{Conclusion And Recommendation}

All participants of the FGDS lacked knowl- edge about folic acid (vitamin b9) and its utilization and were unaware of foods that- contain folic acid. To reduce the incidence of NTDs in this population, awareness of folic acid foods and NTDs should be increased during community visit by health extension workers and antenatal care visits at health facilities. Additionally, appropriate informa- tion about folic acid and its use should be transmitted through appropriate media like the min enamakirliwo program onFM Bahir dar 96.9.

\section{Declarations}

\section{Ethics approval and consent to participate}

Ethical approval was obtained from Amhara Public health Institute ethics committee.

\section{Consent for publication}

Not applicable.

\section{Availability of data and materials}

The datasets used and/or analyzed during the current study are available from the corresponding author on reasonable request.

\section{Competing interests}

The authors declare that they have no competing interests.

\section{Funding}

The authors declare that they did not receive funding for this research from from rotary international .

\section{Authors' contributions}

BM conceptualized the paper. BM,TZ, performed article search, data extraction, and data analysis. BM and TZ did critical review. TZ produced the first draft of the manuscript. All authors contributed to the interpretation, commented on multiple versions, and approved the final manuscript.

\section{Acknowledgments}

The authors would like to acknowledge both FGDS participants and health extension workers, in addition rotary international by funding to accomplishment of this paper. 


\section{References}

[1].A. L. Christianson, C. P. Howson, and B. Modell, "Global report on birth defects: the hidden toll of dying and disabled children," White Plains (NY): March of Dimes Birth Defects Foundation 2006.

[2].World Health Organization, "Fact sheet No 370. October 2012,"

[3].WHO/EURO, "Folic Acid: From research to public health practice," Copenhagen, Den- mark; 2002.

[4].J. Williams, C. T. Mai, J. Mulinare, J. Isenburg, T. J. Flood, and M. Ethen, "Updated estimates of neural tube defects prevented by mandatory folic Acid fortifica- tion - United States, 1995- 2011," MMWR Morb Mortal Wkly Rep.2015; 64:1-5. [5].EUROCAT Website Database, "2015,"

[5].EUROCAT Website Database, "2015," http://www.eurocatetwork.eu/ACCESSPREVALENCEDA

[6].P. Muller, C. Wilkinson, R. Cocci- olone, E. Haan, and Chan., "A: trends instate/populationA based screening for neural tube defects (NTDS," Journal of Obstetrics Gynecology, 1986.

[7].D. B. Shurtleff, "Epidemiology of neural tube defects and folic acid," Cerebrospinal Fluid.Research.2004;1(5).

[8].J. K. Morris and N. J. Wald, "Quantifying the decline in the birth prevalence of neural tube defects in England and Wales," Journal of Medical Screening.1999; 6(4):182-185.

[9].M.Hashmi, "Frequency of consanguinity and its effect on congenital malformation a hospital based study," J Pak Med Assoc. 1997; 47: 75.

[10].G. Sorri and E. Mesfin, "Patterns of neu- ral tube defects at two teaching hospitals in Addis Ababa, Ethiopia a three years ret- rospective study," Ethiopian Medical Jour- nal.2015;53(3): 119-126.

[11].Yitayal A, Tewachew M, Amare S, Women's Awareness and Associated Factors on Preconception Folic Acid Supplementation in Adet, Northwestern Ethiopia, 2016: Im- plication of Reproductive Health. Journal of Nutrition and Metabolism. Volume 2018, Ar- ticle ID 4936080, 7 pages

[12].Wellings K, Jones KG, Mercer CH, Tan- ton C, Clifton S, Datta J, Copas AJ, Erens B, Gibson LJ, Macdowall W, Sonnenberg P, Phelps A, Johnson AM. The prevalence of un- planned pregnancy and associated factors in Britain: findings from the third National Sur- vey of sexual attitudes and lifestyles (Natsal- 3). Lancet. 2013;382:1807-16

[13].Yeasmin SF, Regmi K. A qualitative study on the food habits and related beliefs of pregnant British Bangladeshis. Health Care for Women Int. 2013;34:395-415.

[14].Lassi ZS, Salam RA, Haider BA, Bhutta ZA. Folic acid supplementation during preg- nancy for maternal health and pregnancy outcomes. Review. 2013 ;(3). 
[15].Khoshnood B, Loane M, de Walle H, Arriola L, Addor M-C, Barisic I, Beres J, Bianchi F, Dias C, Draper E, Garne E, Gatt M, Haeusler M, Klungsoyr K, Latos- Bielenska A, Lynch C, McDonnell B, Nelen V, Neville AJ, O’Mahony MT, Queisser-Luft A, Rankin J, Rissmann A, Ritvanen A, Round- ing C, Sipek A, Tucker D, Verellen-Dumoulin C, Wellesley D, Dolk H. Long term trends in prevalence of neural tube defects in Europe: population-based study. BMJ.2015;351:5949.

\section{Supplementary Files}

This is a list of supplementary files associated with this preprint. Click to download.

- annex.docx 